in China and neighbouring countries, particularly focused in the Tien Shan and Pamir Mountain region.

PHILIP RIORDAN ${ }^{*} \dagger$ Department of Zoology, University of Oxford, South Parks Road, Oxford, UK

E-mail philip.riordan@zoo.ox.ac.uk

JUN WANG $\ddagger$ and KUN SHI ${ }^{*} \dagger$ The Wildlife Institute, Beijing Forestry University, Beijing, China

HONGYAN $F u$ and ZHU DabUXILIKE Yanchiwan National Nature Reserve, Subei County, Gansu Forestry Administration, China

Kebiao Zhu and XiaOHu Wang Kashi Wildlife Conservation and Management Division, Xinjiang Forestry Administration, China

${ }^{*}$ Also at: Wildlife Without Borders UK, Oxford, UK $\dagger$ Also at: The Wildlife Institute, Beijing Forestry University, Tsinghua-East, China

$¥$ Also at: Department of Biological Sciences, Manchester Metropolitan University, Manchester, UK

\section{Increasing concern over trade in bat souvenirs from South-east Asia}

Wildlife species are harvested and traded in many forms, including as souvenirs such as claws, ivory jewellery, marine shells and preserved specimens of insects and other small animals. During a visit to Vietnam's Ho Chi Minh City with South-east Asian bat researchers in December 2014 we encountered mounted specimens of bats alongside specimens of insects and other invertebrates for sale in souvenir shops. Although such trade is known in South-east Asia, one particular species, the woolly painted bat Kerivoula picta, stood out. K. picta is a distinctive orange-coloured bat with patches of black on the wing membrane. It occurs from South Asia, southern China and mainland South-east Asia to Sumatra, Java and the Moluccas, although there are few recent records for its eastern range. The asking price for a mounted specimen was c. USD 22, and one mounted with a tube-nosed bat (Murina sp.) was c. USD 21 (USD 14 after discussion) in another shop. Other mounted bat species for sale included pipistrelles (labelled 'Pipistrel') for c. USD 12 each, and fruit bats (Macroglossus sp.), labelled 'dog bats'. SJR has also observed many mounted bats, typically Tylonycteris sp., for sale in tourist markets in China.

The trade in bat specimens goes beyond tourist shops; a search on e-commerce site eBay, on 15 December 2014, using the term 'bat taxidermy' revealed mounted and osteological specimens of several South-east Asian bat species. These included frugivorous species labelled as Cynopterus sp., Macroglossus minimus and Rousettus leschenaultii, and the insectivorous species Hipposideros bicolor, Hipposideros larvatus, K. picta, Miniopterus medius, Otomops formosus, Pipistrellus javanicus, Rhinolophus lepidus, Scotophilus kuhlii and Tylonycteris robustula (although the identification of some specimens may be incorrect). Most sellers were based in the USA, and the others in Indonesia, Thailand and Vietnam. Apart from O. formosus, categorized as Data Deficient on the IUCN Red List, the other species are categorized as Least Concern. Although these sales do not involve threatened species, the legality of the procurement and sale of bat specimens is questionable. In Vietnam, for example, the Law on Forest Protection and Development (2004) affords protection to all wildlife species. It is illegal to hunt, transport, keep, advertize, sell or consume wildlife without a permit; we do not know if the souvenir suppliers and sellers have the necessary permits. One eBay seller based in Vietnam had sold 84 framed K. picta at the time of our search and still had available stock. The prices of $K$. picta specimens on eBay were USD 18.50169.20 , typically more expensive than those we observed in Vietnam. Other websites that retail mounted bats include Amazon, Etsy, Oddities Store and the Evolution Store.

The potential unsustainability of harvesting bats for the souvenir trade is of concern given that we know little of wild bat populations and offtakes. Bats are long-lived and slowly reproducing, with many species already declining and facing future threats as a result of habitat loss. For example, the range-restricted Kitti's hog-nosed bat Craseonycteris thonglongyai-the world's smallest mammal-was threatened by collection for the souvenir trade shortly after its description in 1974 (Hutson et al., 2001, Microchiropteran Bats: Global Status Survey and Conservation Action Plan, IUCN). Although the harvest of bats for bushmeat has been reviewed at a global scale (Mickleburgh et al., 2009, Oryx, 43, 217-234), almost nothing is known of the potential impacts of the souvenir trade on bats. We call for socio-ecological studies on this trade, especially in range countries, to understand the extent of exploitation and the commodity chain. This information is urgently needed to determine whether the trade is sustainable and whether interventions are necessary to curb the trade of such wildlife souvenirs.

We thank the Southeast Asian Bat Conservation Research Unit supported by the National Science Foundation under Grant No. 1051363.

Benjamin P.Y.-H. Lee and Matthew J. Struebig Durrell Institute of Conservation and Ecology, School of Anthropology and Conservation, University of Kent, Canterbury,UK. E-mail benjamin.lee@alumni.nus.edu.sg

STEPHEN J. ROSSITER School of Biological \& Chemical Sciences, Queen Mary University of London, London, UK

Tigga KIngston Department of Biological Sciences, Texas Tech University, Lubbock, Texas, USA 